\title{
Flume weir for quantitative collection of nekton from vegetated intertidal habitats
}

\author{
R. T. Kneib \\ University of Georgia Marine Institute, Sapelo Island, Georgia 31327, USA
}

\begin{abstract}
I describe a flume weir for long-term quantitative sampling of nekton from vegetated intertidal marshes at high tide. The flume weir design is a significant advance over previous methods because it samples a relatively large and precisely defined area $\left(100 \mathrm{~m}^{2}\right)$ without affecting the normal movement patterns of nekton into or out of the sampling area until the moment a sample is required. Sampling by flume weir is neither destructive of the vegetated habitat nor restricted to the marsh edge as are many other methods recently used to sample nekton in intertidal marshes. The mean efficiency with which fish and crustaceans $\geq 30 \mathrm{~mm}$ in length were recovered from flume weirs was in the range 86 to $99 \%$. From July 1988 to June 1990, 20 species of fish and 4 species of crustaceans comprising a total of 47353 individuals ( 15 to $540 \mathrm{~mm}$ in length) were collected in $271 \mathrm{flume}$ weir samples taken from intertidal marsh sites adjacent to Sapelo Island, Georgia, USA. Adults and juveniles of small resident marsh species composed $82.3 \%$ of the total individuals collected. Juveniles of seasonal migrant species, which use marshes as nurseries were also common. The most abundant of these was the white shrimp Penaeus setiferus, which was present only from June to November, but composed $12.9 \%$ of the total nekton collected. Other common seasonal species were mullet Mugil spp. and spot Leiostomus xanthurus, which represented 1.7 and $1.6 \%$ of the total catch, respectively. By providing a means of monitoring nekton densities at sites where conventional gears are clearly inappropriate, the flume weir may allow researchers to address long-standing questions linking marsh production with coastal fisheries. As a management tool, the flume weir may be used by coastal land managers to assign a fisheries value to specific intertidal habitats as part of a process to evaluate marsh mitigation and restoration efforts
\end{abstract}

\section{INTRODUCTION}

Intertidal marshes and other vegetated coastal wetlands are considered important nursery habitats for many fish and crustacean species (Boesch \& Turner 1984). However, attempts to determine the extent to which nektonic organisms use flooded areas of emergent vegetation throughout the intertidal zone have been hampered by the limitations of sampling gear. In salt marshes of the Southeastern US, characterized by extensive stands of Spartina alterniflora and Juncus roemarianus, our understanding of habitat-use by nekton is based largely on samples collected from either unvegetated creek channels (Weinstein 1979, Bozeman $\&$ Dean 1980) or from the edge of the vegetated habitat (e.g. Zimmerman \& Minello 1984, Hettler 1989). Although dense vegetation precludes effective use of conventional sampling gear (i.e. trawls and seines), several techniques have been developed to collect nekton from marshes and other vegetated aquatic environ- ments. Most techniques can be classified as either active or passive methods.

Active methods provide instantaneous samples from a defined area and include: lift-nets (Higer \& Kolipinski 1967), drop-nets (Moseley \& Copeland 1969, Adams 1976), pop-nets (Serafy et al. 1988) and a variety of enclosure traps (Kushlan 1981, Zimmerman et al. 1984, Rozas \& Odum 1987a, Sogard 1989). Most of the active devices are portable and sample a relatively small area $\left(1\right.$ to $\left.9 \mathrm{~m}^{2}\right)$. All active methods result in disturbance or destruction of the habitat either during setting the sampler or collecting the trapped organisms so that it is impossible to sample the same area repeatedly. Some of the devices (i.e. throw traps and drop nets) may not seal properly along the bottom edge when used in the very dense and stiff vegetation found in intertidal marshes.

Passive methods such as gill nets, fyke nets, flume nets (McIvor \& Odum 1986) and block nets (Sikora 1977, Hettler 1989) sample a larger but less precisely- 
defined area. Whether or not these methods disturb or destroy the habitat depends on how the gear is deployed and how the samples are retrieved. Many of these methods are size- or species-selective (e.g. gill nets) and all involve placing intrusive barriers into the environment, which may interfere with normal movement patterns of the nekton. A major problem with passive techniques is that they integrate the sample over time, obscuring specific information about species composition and densities within particular portions of the habitat. For instance, a block net placed in a channel captures nekton for some predetermined time (e.g. all of the ebb tide), but an undetermined area. In order to calculate a density, the investigator must assume that all individuals used the entire area within the drainage of the channel; whether a particular species used all, or only a portion, of the available habitat cannot be determined.

In this paper I describe a flume weir designed to collect quantitative samples of nekton from vegetated, intertidal marshes. This sampler combines the best features of both active and passive devices, while avoiding most of the problems associated with previous methods. The flume weir is a fixed structure that samples a large, precisely-defined area of $100 \mathrm{~m}^{2}$ It can be constructed and used in any regularly-flooded, vegetated intertidal habitat to provide long-term, sitespecific information on habitat-use patterns of juvenile fishes and crustaceans. The sampling area is accessible to swimming organisms moving in any direction and there is virtually no habitat disturbance involved in retrieving the sample.

\section{MATERIALS AND METHODS}

Study site. Two flume weirs were constructed within the vegetated intertidal marsh $\left(31^{\circ} 29^{\prime} \mathrm{N}, 81^{\circ} 16^{\prime} \mathrm{W}\right)$ bordering the upper reaches of the Duplin River, a tidal lagoon located just to the west of Sapelo Island, Georgia, USA. The dominant emergent vegetation at the site is the smooth cordgrass Spartina alterniflora. The study area is twice daily flooded and drained by mixed tides with a mean tidal range of $2.1 \mathrm{~m}$. Much of the vegetated marsh is located relatively high in the intertidal zone ( $\sim 1.9$ to $2.1 \mathrm{~m}$ above mean lower low water), but is inundated by $\sim 92 \%$ of all high tides. Salinity at the study site varied from 5 to $30 \%$, and averaged $22 \%$.

Design and construction. The flume weir consists of 39 permanent posts driven into the marsh surface at $1 \mathrm{~m}$ intervals to support 39 removeable screen panels, which when positioned between the posts, completely enclose a $100 \mathrm{~m}^{2}$ pentagon-shaped sampling area (Fig. 1A). Each support post was constructed of 2 opposing wooden boards $(1.9 \mathrm{~cm} \times 14 \mathrm{~cm} \times 1 \mathrm{~m}$ long) fastened to a wooden stake $(3.8 \mathrm{~cm} \times 4.3 \mathrm{~cm} \times 1.52 \mathrm{~m}$ long) so that a vertical channel $(4.3 \mathrm{~cm}$ wide $\times 5.1 \mathrm{~cm}$ deep $\times 1 \mathrm{~m}$ long) was formed along each side of the post. The posts were installed so that the screen panels fit easily but snugly into the channels on 2 adjacent posts.

The panels were constructed of plastic-coated fiberglass screening (1.2 mm square mesh) held between 2 wooden frames (each $95.25 \mathrm{~cm}$ square $\times 1.9 \mathrm{~cm}$ thick). An end lap (half lap) joint was used at the corners of each frame and the panel components were fastened together by 12 wood screws. Untreated pine lumber was used in the construction of all wooden flume weir components, which were assembled with stainless steel screws so that they could be easily and repeatedly dissassembled for repair when necessary. A sharp knife was used to cut the root mat and excavate shallow, narrow trenches ( $4 \mathrm{~cm}$ wide $\times 4 \mathrm{~cm}$ deep) between the support posts to ensure a tight seal around the bottom of the flume weir when the panels were set in place.

A narrow wooden boardwalk $(-33 \mathrm{~cm}$ wide), elevated $45 \mathrm{~cm}$ above the marsh surface, surrounded the flume weir to provide easy access to the perimeter of the sampling area without disturbing the marsh surface. The boardwalk was constructed of untreated pine planks $(3.8 \mathrm{~cm} \times 14 \mathrm{~cm} \times 3.7 \mathrm{~m}$ long), supported by wooden trestles at intervals of $\sim 1.8 \mathrm{~m}$. The flume weir panels were stored in 6 wooden racks conveniently located around the sampling area and were easily accessible from the boardwalk (Fig. 1).

Two water-filled collecting pits were excavated in the marsh substratum near the flume weir apex, which was deliberately located at the lowest relative elevation in the $100 \mathrm{~m}^{2}$ sampling area (Fig. 2). Preassembled wooden frames were permanently fitted into the pits flush with the marsh surface. The frames maintained the integrity of the pits by reinforcing the corners and prevented the marsh sediments from eroding at the edges of the excavation. Removable wood-framed screen baskets (inside dimensions: $35 \mathrm{~cm} \times 70 \mathrm{~cm} \times 25$ $\mathrm{cm}$ deep) were constructed to fit snugly in to the collecting pit frames. The baskets were fitted with screened covers to prevent nekton from entering the collecting pits between samples. Two pavement bricks, each weighing 1.5 to $2.0 \mathrm{~kg}$, prevented the baskets from floating out of the pit at high tide. Small wooden stands $(14 \mathrm{~cm} \times 40 \mathrm{~cm} \times 15 \mathrm{~cm}$ high) installed next to each collecting pit allowed researchers to remove and replace the baskets without disturbing the marsh surface within the sampling area (Fig. 2).

The flume weir components (i.e. support posts, panels, panel storage racks, collecting pit frames, collecting baskets, boardwalk supports) were preassembled prior to being transported to the field. This phase of the construction required 2 people up to $2 \mathrm{wk}$; the 

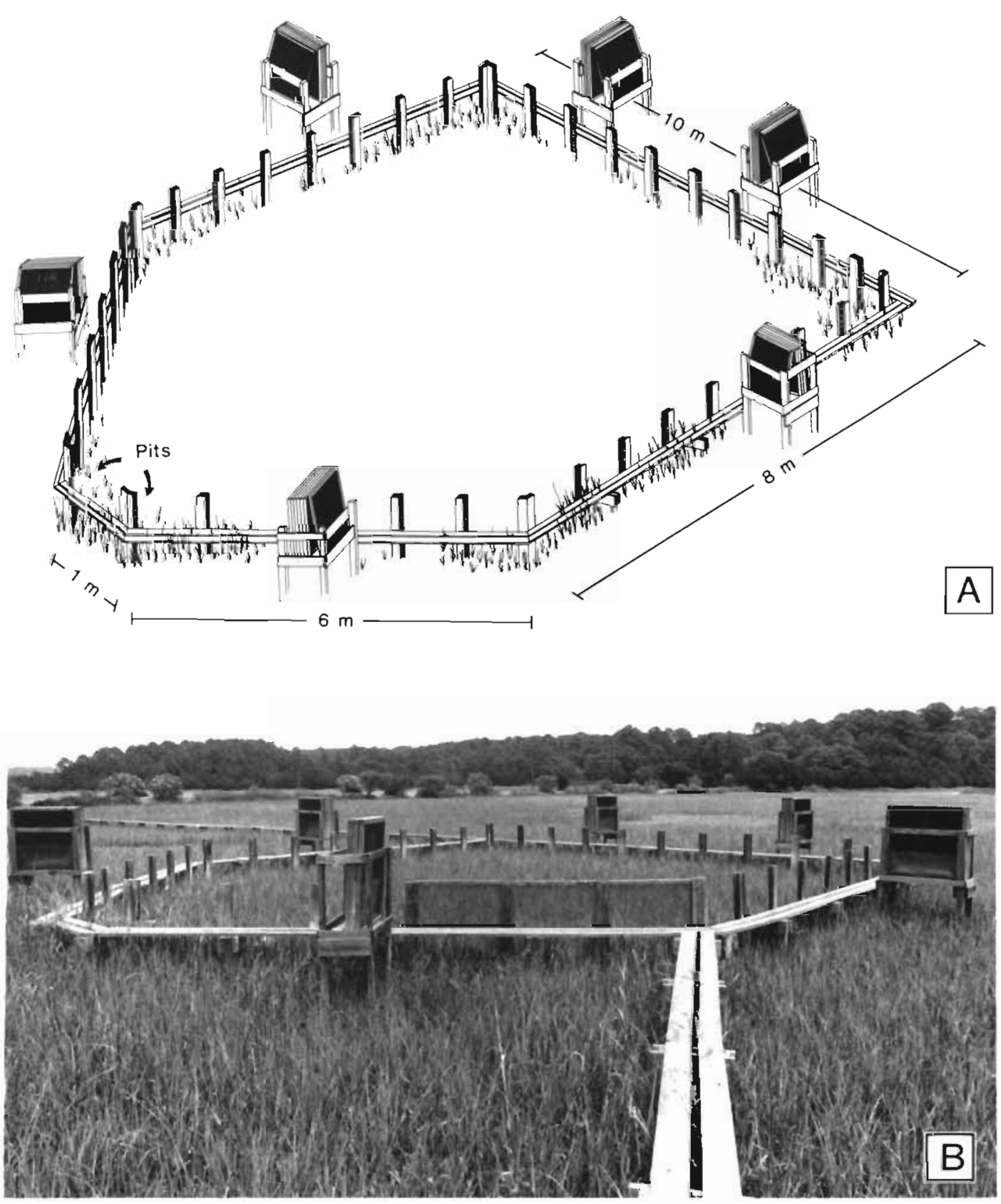

Fig. 1 (A) Diagram of a flume weir, showing placement of support posts, boardwalk and panel storage racks. The dense vegetation within the sampling area was omitted to show structural details. (B) Photograph of a flume weir installed within the intertidal marsh. Three screen panels are in place near the front of the structure. Note the lack of disturbance to the natural vegetation at the site even though nekton samples had been collected frequently from this flume weir for over 1 yr

time required depended on the level of skill in working with the materials. Installation in the field required another 3 to $4 \mathrm{~d}$. During the field installation, care was taken to minimize disturbance in and around the sampling area. Until a permanent narrow boardwalk was installed around the sampling area, workers used moveable temporary boardwalks $(2 \mathrm{~m}$ long, $25 \mathrm{~cm}$ wide) with short $(15 \mathrm{~cm})$ supports at the ends. Because only the supports contacted the marsh substratum, the temporary boardwalks remained a few $\mathrm{cm}$ above the substratum and allowed the workers to move anywhere around the perimeter of the sampling area without permanent damage to the marsh habitat.

Operation of flume weir. Without the screen panels in place, nekton could enter and leave the sampling area from any direction when the tide flooded the 


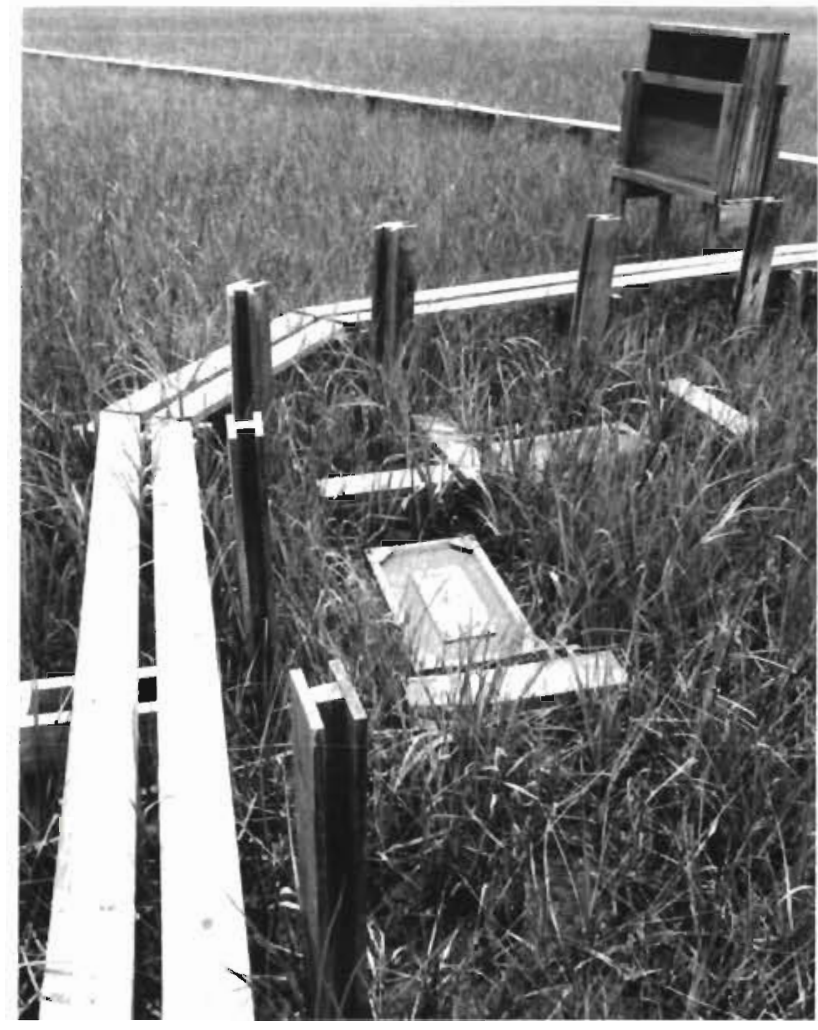

Fig. 2. Photograph of the collecting pit area at the apex of a flume weir showing details of support posts, wooden stands installed next to collecting pits and screen basket covers in place

marsh surface. A sample could be taken at any time during the flood portion of the tidal cycle simply by installing all of the screen panels between the support posts of the flume weir to trap the nekton within the $100 \mathrm{~m}^{2}$ sampling area. In the present study, all of the nearly equal number of day $(n=138)$ and night $(n=$ 133) samples were taken at slack high tide. Two persons could install all 39 panels within 2.5 to $4.0 \mathrm{~min}$, depending on experience and environmental conditions; setting the flume weir panels took slightly longer at night and in the rain, than under more favorable conditions. The placement of panels began at the apex of the flume weir and proceeded around both sides of the sampling area simultaneously so that the two members of the sampling team met in the middle of the $10 \mathrm{~m}$ side (Fig. 1A). After the tide receded from the marsh surface (usually 3.0 to $3.5 \mathrm{~h}$ after slack high tide), nekton entrapped within the sampling area were concentrated in the collecting pits and were easily collected by removing the baskets that lined the pits. All individuals were identified to species and measured. Sizes are reported as total length (TL) in $\mathrm{mm}$. TL of a fish was measured from the tip of the snout to the end of the tail; TL of a shrimp, from the tip of the rostrum to the end of the telson.

Efficiency tests. Although the collecting pits were the deepest, most permanent bodies of water in the sampling area, shallow puddles of residual tidal water often remained after the tide left the marsh surface and could provide a temporary aquatic refuge for nekton that did not find their way into the collecting pits. If large numbers of organisms escaped collection by making use of these temporary aquatic refugia, nekton densities would be significantly underestimated. I used 2 methods to test the efficiency with which nekton were retrieved from the flume weir. In the first method, I set the panels of the flume weir in place and retrieved the sample as described above. However, instead of removing the panels after the first retrieve, they were left in place so that on subsequent flood tides no additional nekton could enter the flume weir but any organisms remaining within the sampling area had additional opportunities to find the collecting pits. I continued to collect nekton from the flume weir after each of the next two consecutive flood tides (for a total of 3 retrieves).

The number of individuals recovered in a series of retrieves tended to follow an exponential decay function. If $n_{\mathrm{x}}$ is the number of individuals captured in retrieve number $x$, regressing $\ln \left(n_{\mathrm{x}}\right)$ on $\ln (x)$ describes a straight line from which I predicted the number of retrieves ( $r$ ) required to capture all of the individuals such that $\ln \left(n_{\mathrm{r}}\right) \leq 0$ (i.e. the number of individuals collected in retrieve $r$ is $\leq 1$ ). Then, I estimated the total number of individuals enclosed within the sampling area by summing the predicted numbers of individuals in all retrieves from 1 to $r$. The cumulative number of individuals collected after each of the 3 actual retrieves was then divided by the predicted total number to provide an estimate of efficiency expressed as the proportion of the total individuals captured after 1,2 and 3 retrieves

From March 1988 to July 1990, I conducted 15 efficiency tests in order to obtain mean efficiency estimates for different species and size classes of individuals. However, because of seasonal changes in abundance, no one species or size class was present in sufficient numbers to estimate efficiency of capture in all 15 tests. A species or size class was included in the analysis if there was sufficient information to estimate efficiency in at least 5 separate tests. The arcsin $V \mathrm{p}$ transformation was applied to all proportional data prior to the calculation of statistics (Sokal \& Rohlf 1981). However, backtransformed means and measures of variance are reported to facilitate interpretation in the present paper.

In the second method to test efficiency of recovery, I set the flume weir panels in place at low tide and then 
added 250 premeasured fish (38 to $96 \mathrm{~mm} \mathrm{TL}$ ) to the sampling area at high tide. After 3 consecutive flood tides and subsequent retrievals, the number and size distribution of the captured fish was compared with the number and sizes of fish initially added. The fish used in this test were mummichogs Fundulus heteroclitus because they are abundant year-round residents of the intertidal marsh and are likely to use residual puddles of tidal water as temporary aquatic refugia in the event of being stranded in the intertidal zone. I conducted this test twice, once in each of 2 flume weirs.

\section{RESULTS}

\section{Species composition of flume weir samples from the intertidal marsh}

Twenty-four species of nekton totaling 47353 individuals in the size range 15 to $540 \mathrm{~mm}$ were captured during the period July 1988 to June 1990 (Table 1). Although the collections included individuals as small as $5.0 \mathrm{~mm}$, I was unable to estimate capture efficiencies for nekton smaller than $15 \mathrm{~mm}$. Species were considered permanent residents of the intertidal marsh if both juveniles and adults were present in the samples. The most common residents included: the mummichog Fundulus heteroclitus, the spotfin killifish Fundulus luciae, the sailfin molly Poecilia latipinna, the sheepshead minnow Cyprinodon variegatus, the daggerblade grass shrimp Palaemonetes pugio, and the marsh grass shrimp Palaemonetes vulgaris. These species accounted for $82.3 \%$ of the total individuals collected and $98.8 \%$ of individuals 15 to $29 \mathrm{~mm}$ TL (Table 1 ).

Other species were considered seasonal migrants because they exhibited a strong temporal pattern of abundance and were represented by only a single life history stage (i.e. juvenile or adult). Numerically, the most important seasonal migrant was the white shrimp Penaeus setiferus, which was present only from June to November, but composed $12.9 \%$ of the total nekton collected. Mullet Mugil spp. and spot Leiostomus xanthurus were the most common seasonally-abundant fish species, representing $1.7 \%$ and $1.6 \%$ of the total

Table 1. Size-specific species composition of samples taken from 2 flume weirs located in the intertidal marsh near the upper reaches of the Duplin River, Sapelo Island, Georgia, USA. Data were pooled from 271 samples of $100 \mathrm{~m}^{2}$ each collected during July 1988-June 1990

\begin{tabular}{|c|c|c|c|c|c|}
\hline \multirow[t]{2}{*}{ Species } & \multicolumn{4}{|c|}{ Size class (TL, mm) } & \multirow[t]{2}{*}{ Total } \\
\hline & $15-19$ & $20-24$ & $25-29$ & $\geq 30$ & \\
\hline \multicolumn{6}{|l|}{ Fishes } \\
\hline Fundulus heteroclitus & 906 & 1463 & 1214 & 14495 & 18078 \\
\hline Fundulus Iuciae & 551 & 1262 & 792 & 1117 & 3722 \\
\hline Mugil spp. & 3 & 3 & 11 & 802 & 819 \\
\hline Leiostomus xanthurus & 12 & 77 & 57 & 588 & 734 \\
\hline Poecilia latipinna & 198 & 71 & 28 & 164 & 461 \\
\hline Fundulus majalis & 1 & 0 & 4 & 396 & 401 \\
\hline Menidia menidia & 0 & 0 & 3 & 111 & 114 \\
\hline Cyprinodon variegatus & 18 & 7 & 2 & 72 & 99 \\
\hline Brevoortia tyrannus & 0 & 0 & 1 & 38 & 39 \\
\hline Bairdiella chrysoura & 0 & 0 & 0 & 25 & 25 \\
\hline Gobionellus smaragdus & 2 & 0 & 2 & 11 & 15 \\
\hline Centropomus undecimalis & 0 & 0 & 0 & 10 & 10 \\
\hline Evorthodus lyricus & 0 & 1 & 1 & 6 & 8 \\
\hline Cynoscion nebulosus & 1 & 0 & 0 & 5 & 6 \\
\hline Elops saurus & 0 & 1 & 0 & 2 & 3 \\
\hline Gobionellus boleosoma & 0 & 0 & 2 & 0 & 2 \\
\hline Eucinostomus argenteus & 0 & 0 & 0 & 2 & 2 \\
\hline Sciaenops ocellatus & 0 & 0 & 0 & 2 & 2 \\
\hline Pogonias cromis & 0 & 0 & 0 & 1 & 1 \\
\hline Anguilla rostrata & 0 & 0 & 0 & 1 & 1 \\
\hline \multicolumn{6}{|l|}{ Decapod crustaceans } \\
\hline Palaemonetes pugio & 6679 & 5671 & 2605 & 1625 & 16580 \\
\hline Penaeus setiferus & 6 & 13 & 33 & 6064 & 6116 \\
\hline Callinectes sapidus & 5 & 7 & 7 & 66 & 85 \\
\hline Palaemonetes vulgaris & 6 & 15 & 2 & 7 & 30 \\
\hline Total nekton: & 8388 & 8591 & 4764 & 25610 & 47353 \\
\hline
\end{tabular}


catch, respectively Although the dominant seasonal migrants were all juveniles, a greater proportion of the individuals were in larger size classes $(97.2 \%$ were $\geq 30 \mathrm{~mm}$ TL) relative to the size distribution of the resident species ( $44.9 \%$ were $\geq 30 \mathrm{~mm} \mathrm{TL}$ ).

\section{Efficiency estimates}

Densities of most species were too low to estimate the efficiency with which each species or size class was captured. However, overall efficiencies may be inferred from values estimated for the more common resident and migrant species (Table 2). Palaemonetes pugio was the only species with sufficient numbers of individuals in each size class to provide an accurate measure of size-specific efficiency. The capture efficiencies of Fundulus luciae and size classes of Fundulus heteroclitus $<30 \mathrm{~mm}$ TL could not be estimated because their numbers often remained constant or increased with consecutive retrieves instead of decreasing as required by the method used to estimate efficiency.

The common resident species (Fundulus heteroclitus and Palaemonetes pugio) were less efficiently removed from the sampling area than were the seasonal migrants (Leiostomus xanthurus and Penaeus setiferus), but at least $85 \%$ of all individuals $\geq 30 \mathrm{~mm}$ TL were captured after 2 retrieves, regardless of species. Cap- ture efficiency decreased for smaller nekton as indicated by the data collected for four size classes of P. pugio (Table 2).

The results of the second method of estimating capture efficiency supported the findings of the first (Fig. 3). Following the release of 250 measured $F$. heteroclitus into each of 2 flume weirs at high tide, 84 and $83 \%$ were recovered from Flume Weirs 1 and 2, respectively on the first retrieve. After a second retrieve, a total of $96 \%$ of the fish added to Flume Weir 1 and $87 \%$ of those added to Flume Weir 2 were recovered. The size distributions of the fish recovered from the flume weirs matched those that were added (Fig. 3).

\section{DISCUSSION}

Testing the absolute efficacy of a field collection method is often difficult because there is no standard against which the effectiveness of the sampling device can be measured. Also, efficacy is a multifaceted issue. For instance, gear avoidance is a problem commonly associated with the use of active devices, but both avoidance and attraction may be important considerations in the use of certain passive sampling devices. Often there is no practical way to test for these biases. However, one testable aspect of the overall efficacy of most methods that have been used to sample nekton in

Table 2. Flume-weir efficiency estimates. Mean cumulative proportion of individuals captured after 1,2 and 3 retrieves. The $95 \%$ confidence intervals are given in parentheses. The number of estimates used in the calculation of means and $95 \%$ confidence intervals is shown as $\mathrm{N}$. Raw data were transformed using arcsin $V$ p; backtransformed means and confidence limits are given in the table

\begin{tabular}{|c|c|c|c|c|}
\hline \multirow[t]{2}{*}{ Species } & \multirow[t]{2}{*}{$N$} & \multicolumn{3}{|c|}{ Number of consecutive retrieves } \\
\hline & & 1 & 2 & 3 \\
\hline \multicolumn{5}{|c|}{ Fundulus heteroclitus } \\
\hline$\geq 30 \mathrm{~mm} \mathrm{TL}$ & 12 & $\begin{array}{c}0.62 \\
(0.49-0.75)\end{array}$ & $\begin{array}{c}0.86 \\
(0.76-0.93)\end{array}$ & $\begin{array}{c}0.90 \\
(0.82-0.96)\end{array}$ \\
\hline \multicolumn{5}{|c|}{ Palaemonetes pugio } \\
\hline$\geq 30 \mathrm{~mm} \mathrm{TL}$ & 8 & $\begin{array}{c}0.72 \\
(0.55-0.86)\end{array}$ & $\begin{array}{c}0.94 \\
(0.81-1.00)\end{array}$ & $\begin{array}{c}0.98 \\
(0.91-1.00)\end{array}$ \\
\hline $25-29 \mathrm{~mm}$ TL & 8 & $\begin{array}{c}0.55 \\
(0.35-0.74)\end{array}$ & $\begin{array}{c}0.79 \\
(0.56-0.95)\end{array}$ & $\begin{array}{c}086 \\
(0.69-0.98)\end{array}$ \\
\hline $20-24 \mathrm{~mm} \mathrm{TL}$ & 9 & $\begin{array}{c}0.47 \\
(0.35-0.60)\end{array}$ & $\begin{array}{c}0.65 \\
(0.47-0.81)\end{array}$ & $\begin{array}{c}0.75 \\
(0.59-0.89)\end{array}$ \\
\hline $15-19 \mathrm{~mm} \mathrm{TL}$ & 5 & $\begin{array}{c}0.42 \\
(0.22-0.62)\end{array}$ & $\begin{array}{c}0.58 \\
(0.36-0.78)\end{array}$ & $\begin{array}{c}0.70 \\
(0.45-0.89)\end{array}$ \\
\hline \multicolumn{5}{|c|}{ Leiostomus xanthurus } \\
\hline$\geq 30 \mathrm{~mm} \mathrm{TL}$ & 7 & $\begin{array}{c}0.97 \\
(0.86-1.00)\end{array}$ & $\begin{array}{c}0.99 \\
(0.96-1.00)\end{array}$ & $\begin{array}{c}1.00 \\
(0.99-1.00)\end{array}$ \\
\hline \multicolumn{5}{|l|}{ Penaeus setiferus } \\
\hline$\geq 30 \mathrm{~mm} \mathrm{TL}$ & 9 & $\begin{array}{c}0.90 \\
(0.77-0.98)\end{array}$ & $\begin{array}{c}0.99 \\
(0.94-1.00\}\end{array}$ & $\begin{array}{c}1.00 \\
(0.97-100)\end{array}$ \\
\hline
\end{tabular}


Fig. 3. Fundulus heteroclitus. Results of flume-weir efficiency test in which 250 fish of known size were added to 2 flume weirs. Initial size distributions are shown in top 2 graphs. Bottom 2 graphs show numbers and size distributions of fish recovered in the first (hatched bars) and second (solid bars) retrieves superimposed on the initial size distributions

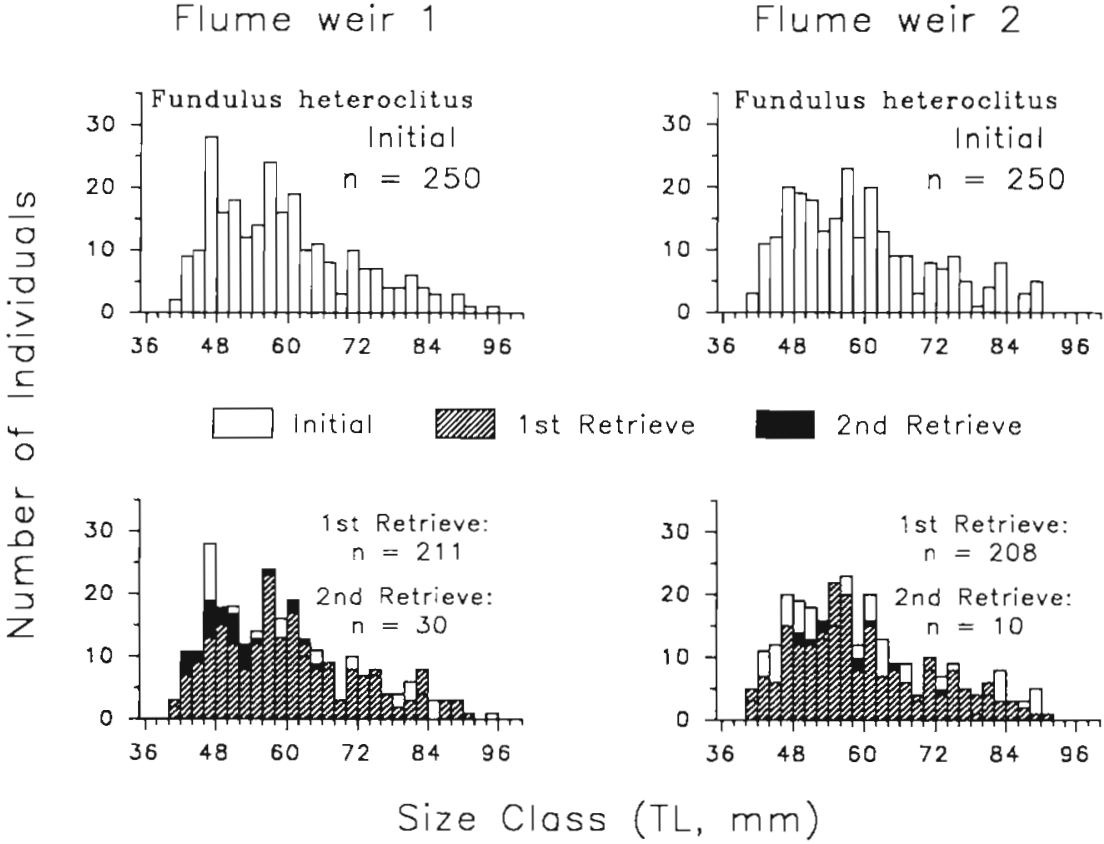

shallow subtidal and intertidal habitats is the efficiency with which entrapped individuals are recovered from the sampling area. This is usually tested by deploying the sampler, adding marked individuals to the entrapped population and then determining the proportion of marked animals retrieved. Zimmerman et al. (1984) used this method to determine that a drop sampler (2.8 $\mathrm{m}$ sample area) designed to take quantitative samples of brown shrimp Penaeus aztecus had an efficiency of $94 \%$ in vegetated marsh habitats. Flume nets (up to $30 \mathrm{~m}^{2}$ sample area) used primarily in vegetated tidal freshwater marshes (McIvor \& Odum 1986, Rozas \& Odum 1987b) had mean efficiencies in the range 46 to $80 \%$, depending on the species tested (McIvor \& Odum 1986). Seines, which are commonly used to sample nekton in tidal marsh creeks, have extremely variable efficiencies and are particularly inefficient for sampling permanent marsh resident species. For example, Weinstein \& Davis (1980) found that seining recovered only 0.5 to $17.8 \%$ of all Fundulus heteroclitus from a section of tidal marsh creek. The efficiency of recovery for spot Leiostomus xanthurus was in the range 6.0 to $90.8 \%$ for individuals $<40 \mathrm{~mm} \mathrm{TL}$, and 0.0 to 50.1 $\%$ for those $>40 \mathrm{~mm}$ TL (Weinstein \& Davis 1980).

Although I used 2 different methods to estimate efficiency in flume weirs $\left(100 \mathrm{~m}^{2}\right.$ sampling area), both produced very similar results (Table 2; Fig. 3) and indicated that flume-weir efficiencies matched or exceeded the efficiencies estimated for other sampling devices. Seasonal migrant species (Leiostomus xanthurus and Penaeus setiferus) were more efficiently removed from the sampling area than were permanent resident species (Fundulus heteroclitus and Palaemonetes pugio). Flume-weir efficiency improved with each consecutive retrieve, but the improvement was not proportional to the effort involved. For example, the mean capture efficiency of $F$. heteroclitus ( $\geq 30 \mathrm{~mm} \mathrm{TL}$ ) rose from 0.62 in the first retrieve to 0.86 in the second and finally 0.90 in the third (Table 2). This represents an improvement of $38.7 \%$ between the first and second retrieves, but only $4.7 \%$ between the second and third retrieves. Given these results, I recornmend that flumeweir samples include at least 2 retrieves, especially if a reasonably accurate density estimate of permanent resident species is an important objective of the sampling program. It is probably unnecessary to have more than 3 retrieves/sample because the slight improvement in efficiency is unlikely to justify the extra effort.

The efficiency of the flume weir was both size- and species-specific (Table 2). Species or size classes of nekton that do not normally leave the intertidal marsh with the ebbing tide were ineffectively sampled by this technique. For example, the flume weirs did not effectively sample Fundulus heteroclitus smaller than $30 \mathrm{~mm}$ TL, Palaemonetes pugio smaller than $15 \mathrm{~mm}$, or any size class of F. luciae. Instead of following the ebbing tide into the creek channels with the adults, the young of these resident species find low-tide aquatic refugia in small, natural puddles of residual tidal water on the marsh surface (Kneib 1984, 1987); F. luciae has a strong affinity for the intertidal zone and does not normally leave this habitat even as an adult (Byrne 
1978. Kneib 1978\}. Small size classes of $F$. heteroclitus and $P$. pugio, and all size classes of $F$. luciae, often were less abundant in the first than in subsequent retrieves. Predation by larger nekton could explain this observation, but because the smaller individuals of these resident species have a propensity for remaining in the intertidal marsh at low tide and are capable of using alternative aquatic refugia, it is more like that they actively avoided the collecting pits when larger nekton were present.

Flume weirs can be used to quantify and compare high tide habitat-use patterns of nekton in a variety of intertidal marsh types. Their use is not restricted to areas adjacent to tidal creeks or open bodies of tidal water as are flume nets (McIvor \& Odum 1986), modified block nets (Hettler 1989) or large drop traps that are deployed from a boat (Zimmerman et al. 1984). They were designed specifically to sample vegetated habitats that are subject to a predictable pattern of tidal flooding. I do not recommend their use in areas with unpredictable tides (e.g. wind-controlled) or in intertidal habitats characterized by little or no natural emergent structure (e.g. open tidal flats). A predictable temporal pattern of tidal flood and ebb is crucial for developing a schedule both to set the flume weir panels and to retrieve the sample. In a habitat with abundant natural structure (e.g. vegetated marsh), it is reasonable to expect nekton neither to avoid nor be attracted to the sampling area as a result of the flume weir structure because until the panels are in place, vertical posts, which are in the same orientation as the natural structure (Fig. 1B), are the only underwater structural addition to the habitat. There are no walls or barriers as there are in flume nets (Mcivor \& Odum 1986) and block nets (Hettler 1989) to repel or guide nekton either into or out of the sampling area. However, in a habitat containing little or no natural emergent structure (e.g. tidal flat), the flume weir would be a relatively significant structural addition and problems related to attraction or avoidance by nekton are likely to be a more important consideration. The boardwalk surrounding the flume weir could be especially problematic in unstructured habitats, where it would cast a distinct shadow that is likely to attract fish. In the highly structured environment of the vegetated marsh (Fig. 1B), shade from the boardwalk is added to that of the vegetation, which also interrupts the distinct edge of the shadow cast by the boardwalk and likely reduces its effect to attract fish. The major contribution of the boardwalk is to minimize disturbance to the collecting site (Fig. 1B), which I believe outweighs its potential to bias flume weir samples from a vegetated habitat.

Flume weirs capture nekton from a precisely defined, but much larger area than throw traps (Kushlan 1981, Rozas \& Odum 1987a, Sogard 1989) and drop traps
(Zimmerman et al. 1984). This should reduce the portion of sample variance attributable to gear avoidance, small-scale patchy distribution patterns and other problems associated with small sample unit size. Although the flume weir described in this paper sampled an area of $100 \mathrm{~m}^{2}$, one may construct a flume weir of any size. Practical considerations will probably dictate the size of the unit for a given project. Increasing the size of the flume weir will increase the amount of time required to completely enclose the sampling area and decreasing the size will amplify biases associated with small sample units.

The major disadvantages of the flume weir are that it samples at a fixed location and requires considerable initial effort in construction. These may be especially formidable problems if large numbers of simultaneous replicates are required in the sampling program. However, once installed, a flume weir may be expected to function for at least 2 to 3 yr with minimal maintenance. A decrease in the effectiveness of the flume weir may develop with time as a result of several minor problems including damage to panels, the accumulation of sediment in the collecting pits, and erosion. Panels are most frequently damaged between samples by rodents, which build nests among the stacked panels in the storage racks. I recommend that at least 2 spare panels be stored at each flume weir site to avoid missing a sample as a result of such panel damage. Sedimentation in the collecting pits is not preventable but can be controlled by periodically dredging the pits. The frequency of this bit of maintenance depends on local sedimentation rates.

The loss of nekton from the sample as a result of predation in the collecting pits may be a problem in certain areas, especially where piscivorous birds are abundant. This was not the case in the present study However, if predation by birds is an important consideration, a screen cover or solid baffle suspended a few $\mathrm{cm}$ above the collecting pits may help to reduce this source of loss. Examination of gut contents from fish collected in the flume weir suggests that losses due to nekton feeding on each other in the collecting pits were low. I believe there are 3 reasons to expect minimal losses from predation in the collecting pits: (1) Most nekton follow the tide onto the vegetated marsh surface to feed on a variety of abundant benthic invertebrates so that by the time they become concentrated in the collecting pits (on the ebbing tide), their guts are already full of small benthic prey. (2) The sample is collected soon after the tide has left the marsh surface and so there is little time for predation to occur. (3) The oxygen level declines as large numbers of nekton become concentrated in the collecting pits. Respiration undoubtedly has precedence over feeding under such conditions. 
Erosion of the marsh substratum adjacent to the panels is perhaps the most serious and difficult problem to control. The narrow trenches cut in the substratum between the support posts to insure that each panel seals tightly at the bottom may widen as a result of the hydraulic pressure associated with the placement and removal of panels. This results in pools of water that may be used by nekton as low tide aquatic refugia, reducing the effectiveness of the collecting pits to concentrate the sample. Under these conditions, efficiency can be improved by dip-netting nekton from pools adjacent to the panels at the time of sample retrieval. At sites where erosion is most likely to occur (e.g. the substratum is not firmly bound by a dense root mat), I recommend using wooden boards to reinforce the sides of the trenches between the panel support posts. The boards should be installed so that the top edges are even with the marsh surface and do not interfere with the placement of panels or the movement of water or nekton into or out of the sampling area.

Vegetated estuarine habitats are ecologically active sites of considerable interest to both research scientists and coastal land managers. Estuarine nekton are both more abundant and more difficult to sample in vegetated habitats than in adjacent unvegetated areas (e.g. Rozas \& Odum 1987a, Heck et al. 1989, Sogard 1989). By providing a means of monitoring nekton densities accurately at sites where the use of most gears is clearly inappropriate, the flume weir can provide estuarine researchers the means to address longstanding problems involving the dynamics of energy transformations within estuarine ecosystems and the links between marsh production and coastal fisheries (Boesch \& Turner 1984). The flume weir also may become an important tool in the management of coastal wetlands by providing an objective basis upon which managers may assign a fisheries- or nursery-function value (Hettler 1989) to specific intertidal habitats as part of a process to evaluate marsh mitigation and restoration efforts.

Acknowledgements. I thank D. Goshorn, W Hettler, M LaSalle and L. Rozas for discussions, comments and suggestions that improved the paper. Numerous individuals were involved in this study; I am especially grateful to F. Anderson, W. Leslie, J. Parker and S. Somerlot for helping to construct the flume weirs and for maintaining a timely sampling schedule under a variety of field conditions. C. Ingram drafted the illustration of the flume weir; photographs were taken by E. Hedick. This work is the result of research sponsored by the NOAA Office of Sea Grant, US Department of Commerce (Grant No. NA88AA-D-SG098). The US Government is authorized to produce and distribute reprints for governmental purposes, notwithstanding any copyright notation that may appear herein. This paper is Contribution No. 681 of the University of Georgia Marine Institute.

\section{LITERATURE CITED}

Adams, S. M. (1976). The ecology of eelgrass, Zostera marina (L.), fish communities. I. Structural analysis. J. exp. mar. Biol. Ecol. 22: 269-291

Boesch, D. F., Turner, R. E. (1984). Dependence of fishery species on salt marshes: the role of food and refuge Estuaries $7(4 \mathrm{~A})$ : $460-468$

Bozeman, E. L., Jr, Dean, J. M. (1980). The abundance of estuarine larval and juvenile fish in a South Carolina intertidal creek. Estuaries 3: 89-97

Byrne, D. M. (1978). Life history of the spotfin killifish, Fundulus luciae (Pisces: Cyprinodontidae), in Fox Creek Marsh, Virginia. Estuaries 1: 211-227

Heck, K. L., Jr, Able, K. W., Fahay, M. P., Roman, C. T (1989). Fishes and decapod crustaceans of Cape Cod eelgrass meadows: species composition, seasonal abundance patterns and comparison with unvegetated substrates. Estuaries 12: 59-65

Hettler, W. F., Jr (1989). Nekton use of regularly-flooded saltmarsh cordgrass habitat in North Carolina, USA. Mar. Ecol. Prog. Ser. 56: 111-118

Higer, A. L., Kolipinski, M. C. (1967). Pull-up trap: a quantitative device for sampling shallow-water animals. Ecology 48: $1008-1009$

Kneib, R. T (1978). Habitat, diet, reproduction and growth of the spotfin killifish, Fundulus luciae, from a North Carolina salt marsh. Copeia 1978: 164-168

Kneib, R. T. (1984). Patterns in the utilization of the intertidal salt marsh by larvae and juveniles of Fundulus heteroclitus (Linnaeus) and Fundulus luciae (Baird). J. exp. mar. Biol. Ecol. 83: 41-51

Kneib, R. T. (1987). Seasonal abundance, distribution and growth of postlarval and juvenile grass shrimp (Palaemonetes pugio) in a Georgia, USA, salt marsh. Mar. Biol. 96 $215-223$

Kushlan, J. A. (1981). Sampling characteristics of enclosure fish traps. Trans. Am. Fish. Soc. 110: 557-562

McIvor, C. C., Odum, W. E. (1986). The flume net: a quantitative method for sampling fishes and macrocrustaceans on tidal marsh surfaces. Estuaries 9: 219-224

Moseley, F. N., Copeland, B. J. (1969). A portable drop-net for representative sampling of nekton. Publs Inst. mar Sci Univ. Tex. 14: 37-47

Rozas, L. P., Odum, W. E. (1987a). Fish and macrocrustacean use of submerged plant beds in tidal freshwater marsh creeks. Mar. Ecol. Prog. Ser 38: 101-108

Rozas, L. P., Odum, W. E. (1987b). Use of tidal freshwater marshes by fishes and macrofaunal crustaceans along a marsh stream order gradient. Estuaries 10: 36-43

Serafy, J. E., Harrell, R. M., Stevenson, J. C. (1988). Quantitative sampling of small fishes in dense vegetation: design and field testing of portable 'pop-nets' J. appl. Ichthyol. 4: $149-157$

Sikora, W. B. (1977). The ecology of Palaemontes pugio in a southeastern salt marsh ecosystem with particular emphasis on production and trophic relationships. Ph.D Dissertation, Univ. South Carolina, Columbia, South Carolina

Sogard, S. M. (1989). Colonization of artificial seagrass by fishes and decapod crustaceans: importance of proximity to natural eelgrass. J. exp. mar. Biol. Ecol. 133: $15-37$

Sokal, R. R., Rohlf, F. J. (1981). Biometry. W. H. Freeman and Company, San Francisco 
Weinstein, M. P. (1979). Shallow marsh habitats as primary nurseries for fishes and shellfish, Cape Fear River, North Carolina. Fish. Bull. U.S. 77: 339-357

Weinstein, M. P., Davis, R. W (1980). Collection efficiency of seine and rotenone samples from tidal creeks, Cape Fear River, North Carolina. Estuaries 3: 95-105

This article was submitted to the editor
Zimmerman, R. J., Minello, T J. (1984). Densities of Penaeus aztecus, Penaeus setiferus, and other natant macrofauna in a Texas salt marsh. Estuaries $7(4 \mathrm{~A}): 421-433$

Zimmerman, R. J., Minello, T. J., Zamora, G. (1984). Selection of vegetated habitat by brown shrimp, Penaeus aztecus, in a Galveston Bay salt marsh. Fish. Bull. U.S. 82: 325-336

Manuscript first received: March 19, 1991

Revised version accepted: June 5, 1991 